\title{
Awareness of Infection Control Practices in Health Care Workers in Tertiary Care Hospital
}

\author{
S. Aswathi and P. Neelusree* \\ Saveetha Medical College, Chennai,India \\ *Corresponding author
}

\section{A B S T R A C T}

\section{Keywords \\ Nosocomial infections, Health care worker, Bio medical waste, Hand hygiene, Health care associated infections}

Article Info

Accepted:

15 August 2019 Available Online: 10 September 2019
Healthcare acquired infections also known as nosocomial infection are associated with increased morbidity and mortality among hospitalized patients and healthcare workers to an increased risk of infections. This study explores the knowledge and practices of infection control practices among health care workers in Saveetha medical college which is a tertiary care hospital. This is a cross-sectional study. A self-administered structured questionnaire was distributed to the study group (of CRRIs and nurses). Data on knowledge and practice of infection control were obtained and analyzed. Study population was selected by convenience sampling. Out of $225 \mathrm{HCW}, 88.5 \%$ of the respondents had good knowledge and implementation in Hand hygiene. In case of case of personal protective equipment $90.6 \%$ of the HCW use disposable masks, this is much more than the usage of disposable aprons and disposable gloves. $99.5 \%$ are aware of the management of exposure to blood borne virus. And based on my study $100 \%$ are aware of ways of accidental exposure \& aware of management of the risks of blood borne virus. $100 \%$ of the health care workers in my study are vaccinated against these viruses. $100 \%$ of the HCW are aware of the usage of colour coded bins but only $90.6 \%$ are using them. Knowledge and awareness of infectious control among health care workers in our hospital is good but the practice is a little less efficient. Training workshop on infection control should be organised for all health care workers to reduce noso-comial infections.

\section{Introduction}

The need for infection control in healthcare facilities is needed to prevent Healthcare associated infections (HCAIs) which are also known as nosocomial infection. HCAI is defined as an infection occurring in a patient during the process of care in a hospital or other healthcare facility which was not present or incubating at the time of admission $^{[1]}$ It contributes to significant morbidity and mortality, longer duration of hospitalization, as well as increase in the cost of treatment in both the wealthy and the resource poor countries.

Globally, hundreds of millions of people are affected every year by avoidable infections in health care. In this respect, healthcare associated infections (HCAIs) affect patients, 
healthcare workers (HCWs), support staff, medical students and patient attendants ${ }^{(10)}$. The associated burden of disease related to HCAIs is extremely high and the impact of HCAIs implies prolonged hospital stay, longterm disability, increased resistance of microorganisms to antimicrobials, massive additional financial burden for health systems, high costs for patients and their family, and unnecessary deaths ${ }^{(11,12) .}$ In the developed world the HCAI is reported to be $15 \%$ among hospitalized patients while it is as high as $37 \%$ for patients admitted into the Intensive Care Unit ${ }^{[1]}$ The prevalence in developing countries is somewhat higher with up to $19 \%$ prevalence of HCAI among hospitalized patients. HCAIs accounted for 16 million additional hospital stay in Europe with estimated total costs of $€ 7$ billion. In the United States, the added expenditure as a result of HCAI is in excess of $\$ 4.5$ billion ${ }^{[2,3]}$ while in the United Kingdom, a mortality rate of $13 \%$ and a prolongation of hospital stay by a factor of 2.5 was reported ${ }^{[4]}$. The worldwide estimated indicated more than 1.4 million people are suffering from infections acquired in hospitals. These risk is $2-20$ times higher in developing countries ${ }^{(11,12) .}$ Despite the simplicity and clarity of precautions; understanding how poor practice could fuel up the transmission, the practice among health care worker is still low. This problem is exacerbated in resource limited settings, like Africa ${ }^{(13,14) \text {. }}$

With not sufficient practice of infection prevention, the risk of acquiring infections through exposure to blood, body fluids or contaminated materials in healthcare facilities is very high $^{(5,6)}$ It is a healthcare setting challenge as the basic idea that healthcare is meant to make people well (7). Clearly, inefficiency in infection prevention and control measures has a number of consequences ${ }^{(8,9) \text {. }}$
Conversely, many tertiary care hospitals have undertaken a multitude of initiatives to protect patients and HCWs by setting standards and guidelines. Compliance with infection prevention measures is the only way to reduce and protect HCWs, patients and the community from the occurrence of HCAIs. On top of this, various multifaceted factors extremely play a great role to achieve the goal of infection prevention, like adequate knowledge towards infection prevention, availability of personal protective equipments and materials, human power, training, policy and guidelines and essential environmental health conditions. Hence, it is important that HCWs must know and use the recommended infection prevention measures accordingly.

\section{Materials and Methods}

Study area, period and design: A facility based cross-sectional study was conducted from January to March 30, 2019, in Saveetha medical college, Chennai. A total of 225 health care workers were analysed in this study.

Sources and study population: HCWs (nurses, MBBS interns and postgraduates) working in Saveetha medical college were considered as sources population. From all, HCWs who were working in Saveetha medical college randomly selected $225 \mathrm{HCWs}$ was the study population.

Data collection: A structured questionnaire which was prepared was used to collect the data. I personally collected all the data through face-face interview. It was also distributed in a few departments in the hospital and the data was filled by the individual itself.

Operational definition: Infection prevention practices of HCWs were assessed for main components of infection prevention measures like hand hygiene practices, utilization of 
personal protective equipment (PPE), healthcare waste management practices, instrument decontamination and disinfection practice, spillage management and clinical environment. There were twenty-six questions which were either yes or no or MCQs or one word answers.

Data processing: After data collection, each questionnaire was checked for completeness, missings and edited for other errors. Each part of the questionnaire was then analysed and all the answers for each subdivision was counted amd the percentage of each answer for every question was analysed. Analysis like pie charts and bar diagrams were computed.

\section{Results and Discussion}

Based on a study on the awareness of infectious control practices among 225 health care workers in a tertiary care hospital the results in each division of the study was:

\section{1) Hand hygiene}

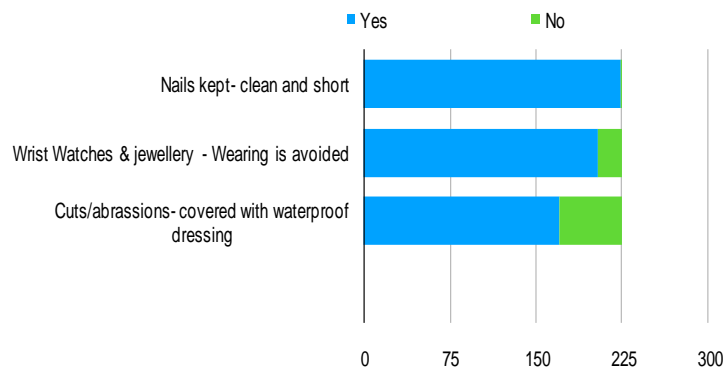

\section{2) Personal protective equipment}

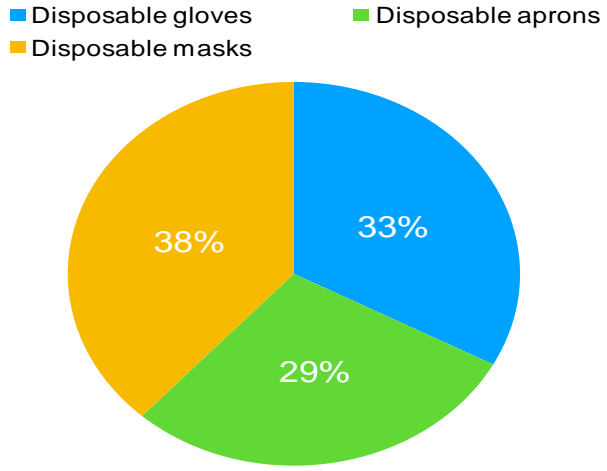

3) Sharp instruments

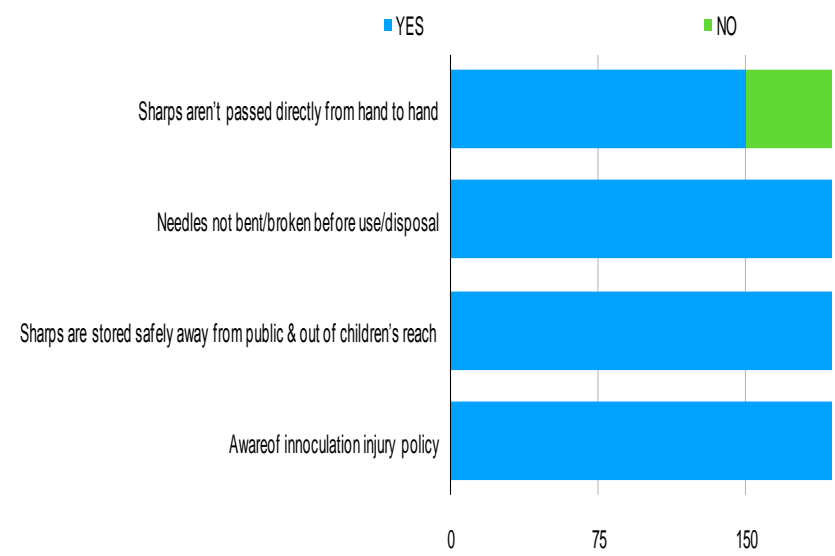

4) Disposal of wastes
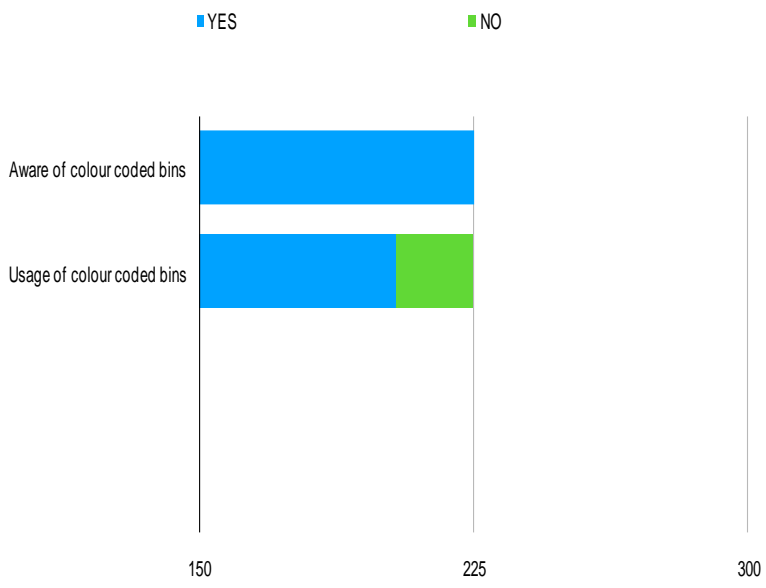

\section{5) Specimen sample}

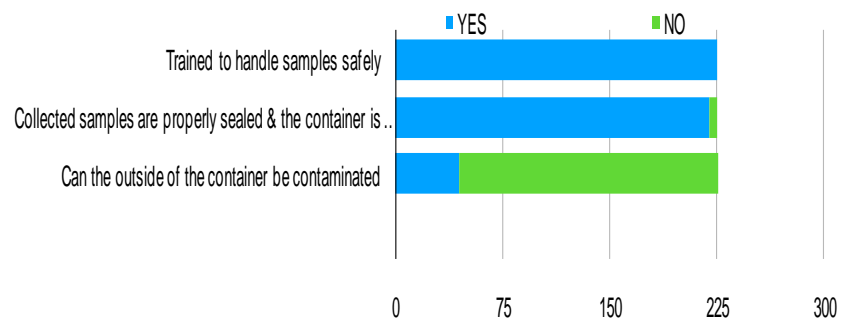

\section{6) Blood and body fluid management}

In case of any spillages, about $99.8 \%$ the spillage is cleared off immediately within 2 mins. The other $0.2 \%$ is also cleared off within a short time range within 5 mins. The blood and the body fluid spillageis managed 
very efficiently and the side effects of spillage is $100 \%$ known to all the health care workers. However the results in detail are given below

\section{A) Cleaning}
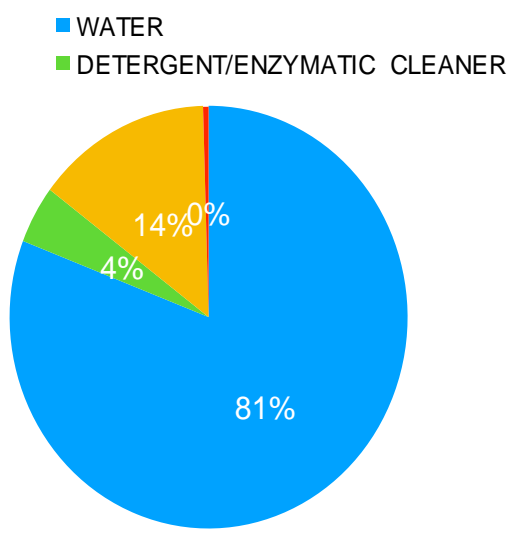

B) Disinfection

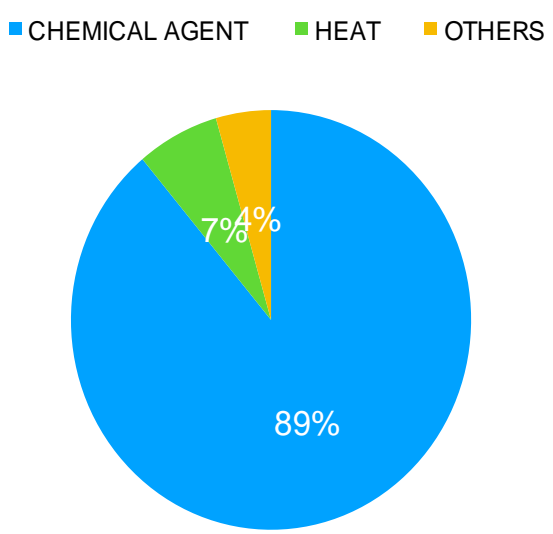

\section{C) Sterlization of Patient's equipment}

$100 \%$ of all the patient equipment is already pre-sterilised. Other methods are also rarely used.

D) Aware of risks associated with not decontaminating patient's equipments

$100 \%$ of the health care workers are completely aware of the risks associated with not decontaminating patient's equipments properly.

\section{Exposure to blood borne viruses}

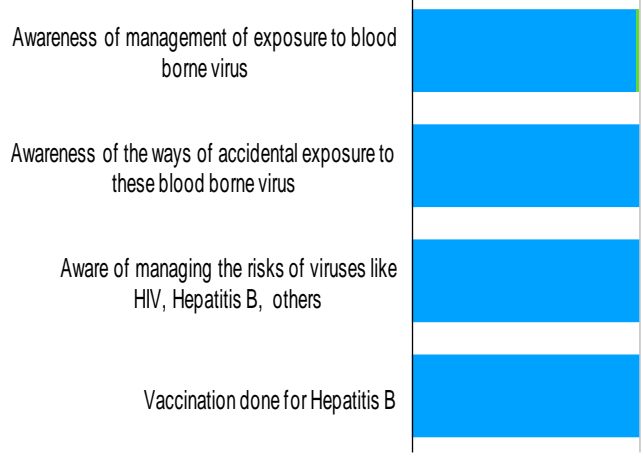

Infection prevention practice is ${ }^{152}$ fundamental to quality of care and essential to protect HCWs, patients and communities from tremendous risks. This study attempted to assess infection prevention practice of HCWs in Saveetha Medical College.

In case of hand hygiene out of $225 \mathrm{HCW}$, $88.5 \%$ of the respondents had good knowledge and implementation. Hand hygiene was higher in our study than the study done in Ludhiana (41.3\%) among nurses working in ICU settings of tertiary care hospital.

Literally all the HCWs use personal protective equipment. Majority of them use disposable marks. The use percentile is $90.6 \%$ in our study, it was higher than the study on personal protective equipment use among health care providers, Tamil Nadu which was conducted among 862 HCPs who work outside the operation theatre (OT) and ICU, appropriate uses of PPE were only 156 $(18.1 \%)$. It was lower than the study conducted on PPE Knowledge and Practices among Nurses Working at Al-Baha King Fahad Hospital, Saudi Arabia where overall awareness amongst study respondents was $93 \%$.

Bio medical Waste management is done very well in the hospital. They have colour coded bins everywhere. $100 \%$ of the $\mathrm{HCW}$ are 
aware of the usage of colour coded bins. This was higher in our study than a study of biomedical waste management at a tertiary care hospital in Goa, India by Piyush Kumar and Frederick $\mathrm{S}$ Vaz which was overall 96.5\%. Only $90.6 \%$ of HCWs are using them in our study.

Most of the HCWs are aware of the management of exposure to blood borne virus. $100 \%$ of the study population is aware of the ways of accidental exposure to these blood borne virus. $100 \%$ of my study population are aware of the management of the risks of blood borne virus. $100 \%$ of my study population was also vaccinated against hepatitis B.

The HCWs of Saveetha Medical College are very well aware of infectious control pratices. My study population had a $100 \%$ result in the awareness in infectious control practices. $100 \%$ of the HCWs were previously trained in the management of infectious control practices.

In this study ninety-one percentile of my study population had good knowledge in infectious control practices.

In conclusion, infection prevention practice is fundamental to quality of care and essential to protect HCWs, patients and communities from tremendous risks. The need for infection control in healthcare facilities is needed to prevent Healthcare associated infections (HCAIs).

\section{References}

1. Geneva, WHO 2009

2. Haley RW, Culver DH, White JW, Morgan WM, Emori TG, Munn VP, et al. The efficacy of infection surveillance and control programs in preventing nosocomial infections in US hospitals.
Am J Epidemiol. 1985;121:182-205.

3. Martone WJ, Jarvis WR, Culver DH, Haley $R W$. Incidence and nature of endemic and epidemic nosocomial infections. In: Bennett JV, Brachman PS, editors. Hospital Infections. 3rd ed. Boston: Little, Brown and Co; 1992. pp. 57796.

4. National Audit Office. The Management and Control of Hospital Acquired Infection in Acute NHS Trusts in England. London: Stationery Office; 2000

5. Federal Ministry of Health of Ethiopia, author. National Infection Prevention Guidelines for Healthcare Facilities in Ethiopia. 1sted. Addis Ababa, Ethiopia: Disease Prevention and Control Department; 2005.

6. Federal Ministry of Health of Ethiopia, author. Infection prevention and patient safety-reference manual for service providers and managers in healthcare facilities of Ethiopia. 2nd ed. Addis Ababa, Ethiopia: Federal Ministry of Health; 2012.

7. Alice WG, Simon MK, Elijah N, Z.Ngalo OA. Health Care Workers Adherence to Infection Prevention Practices and Control Measures: A Case of a Level Four District Hospital in Kenya. American Journal of Nursing Science. 2015

8. Canadian Union of Public Employees (CUPE), author Healthcare acquired infections: A backgrounder. 2009. [January 13, 2016].

9. Adams J, Bartram J, Chartier Y. Essential Environmental Health Standards in Health Care. Geneva, Switzerland: WHO; 2008

10. WHO, UNICEF, SHARE, author. Water, sanitation and hygiene in health care facilities: Global strategy, burden of disease, and evidence and action priorities, workshop report. London, 
United Kingdom: WHO; Available at: http://www.who.int/water_sanitation_he alth/healthcare_waste/module16.pdf

11. Adams J, Bartram J, Chartier Y. Essential Environmental Health Standards in Health Care. Geneva, Switzerland: WHO; 2008

12. Mongolia: Fifth Health Sector Development Project, author. Subsector Analysis (Summary): Hospital Hygiene and Infection Prevention and Control. 2012. [October 25, 2015]. Available at https://www.adb.org/sites/default/files/lin ked.../45009-002-mon-oth-03.pdf.

13.Gammon J, Morgan-Samuel H, Gould D. A review of the evidence for suboptimal compliance of healthcare practitioners to standard/universal infection control precautions. Journal of Clinical Nursing. 2008

14. Hu TA, Anh NQ, Chau NQ, Hung NV. Knowledge, Attitude and Practices Regarding Standard and Isolation Precautions Among Vietnamese Health Care Workers: A Multicenter CrossSectional Survey. Intern Med. 2012

\section{How to cite this article:}

Aswathi, S. and Neelusree, P. 2019. Awareness of Infection Control Practices in Health Care Workers in Tertiary Care Hospital. Int.J.Curr.Microbiol.App.Sci. 8(09): 276-281. doi: https://doi.org/10.20546/ijcmas.2019.809.033 